San Jose State University

SJSU ScholarWorks

Faculty Research, Scholarly, and Creative Activity

$11-3-2020$

\title{
How Perceptions of Work-Life Balance and Technology Use Impact upon Creativity in Collaborative Spaces
}

\author{
Carlotta Cochis \\ University of Modena and Reggio Emilia \\ Elisa Mattarelli \\ San Jose State University, elisa.mattarelli@sjsu.edu \\ Fabiola Bertolotti \\ University of Modena and Reggio Emilia \\ Anna Chiara Scapolan \\ University of Modena and Reggio Emilia \\ Fabrizio Montanari \\ University of Modena and Reggio Emilia
}

See next page for additional authors

Follow this and additional works at: https://scholarworks.sjsu.edu/faculty_rsca

Part of the Performance Management Commons, and the Technology and Innovation Commons

\section{Recommended Citation}

Carlotta Cochis, Elisa Mattarelli, Fabiola Bertolotti, Anna Chiara Scapolan, Fabrizio Montanari, and Paula Ungureanu. "How Perceptions of Work-Life Balance and Technology Use Impact upon Creativity in Collaborative Spaces" Digital Transformation and Human Behavior: Innovation for People and Organisations (2020). https://doi.org/10.1007/978-3-030-47539-0_16

This Contribution to a Book is brought to you for free and open access by SJSU ScholarWorks. It has been accepted for inclusion in Faculty Research, Scholarly, and Creative Activity by an authorized administrator of SJSU ScholarWorks. For more information, please contact scholarworks@sjsu.edu. 


\section{Authors}

Carlotta Cochis, Elisa Mattarelli, Fabiola Bertolotti, Anna Chiara Scapolan, Fabrizio Montanari, and Paula Ungureanu 


\title{
HOW PERCEPTIONS OF WORK-LIFE BALANCE AND TECHNOLOGY USE IMPACT UPON CREATIVITY IN COLLABORATIVE SPACES
}

\author{
Carlotta Cochis ${ }^{1}$, Elisa Mattarelli ${ }^{2}$, Fabiola Bertolotti ${ }^{1}$, Anna Chiara Scapolan ${ }^{3}$, Fabri- \\ zio Montanari ${ }^{3}$, Paula Ungureanu ${ }^{1}$ \\ ${ }^{1}$ Department of Sciences and Methods for Engineering (DISMI), University of Modena and \\ Reggio Emilia, Via Giovanni Amendola, 2, 42122 Reggio Emilia RE, Italy \\ ${ }^{2}$ Department of Management, San Jose State University, One Washington Square, San Jose \\ CA 95112, USA \\ ${ }^{3}$ Department of Communication and Economics, University of Modena and Reggio Emilia, \\ Viale Antonio Allegri, 9, 42121 Reggio Emilia RE, Italy.

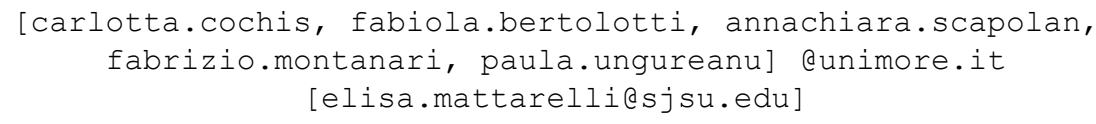

\begin{abstract}
This paper unpacks creative processes in collaborative spaces (CS). We focus on how the positive resources related to wellbeing and work-life balance derived from working in CS interplay with the use of collaborative technology in affecting individual creativity. We conducted a survey study with individuals working in 27 different CS in Italy. We propose and find a positive relationship between the perceived level of work-life balance satisfaction and individual creativity. Instead we do not find a significant relationship between the frequency of technology mediated interactions with external actors and individual creativity. Furthermore, the relationship between work-life balance and creativity is negatively moderated by technology mediated interactions with external actors. In other words, an intense use of collaborative technology with actors external to the CS can generate perceptions of overload thus making the impact of work-life balance on creativity not significant. We conclude with theoretical and practical implications.
\end{abstract}

Keywords: creativity, collaborative space, collaborative technology, work-life balance.

\section{Introduction}

Collaborative spaces (CS), such as incubation spaces, social innovation hubs, fab labs, cultural hubs, co-working spaces, and technology parks bring together different actors 
to favor interactions and knowledge sharing and therefore stimulate creativity in individuals, groups, and organizations. Despite the increased diffusion of collaborative spaces, few studies have empirically investigated what might sustain or impair their outcomes, especially in relation to creativity and innovation. Most of the literature explores how the physical properties of the space (e.g., light, noise levels, furniture, layout, e.g. [1-3] impact individual or group creativity (for a relevant discussion see Moultrie [4]). Collaborative spaces are designed and built following the assumption that face-to-face contact has a positive impact on the propensity of individuals with different backgrounds to interact and exchange ideas [5], thus favoring the development of a sense of creative community [6]. Moreover, the creation of a collaborative space within organizations or in public spaces is often associated to smart work strategies intended to favor individual well-being and work-life balance. For instance, smart work centers and co-working spaces are set up to enhance temporal and spatial flexibility of workers. In these collaborative spaces a variety of potential users, including public and private employees, free-lancers, entrepreneurs, small and micro-businesses, operate taking advantage of several technological resources and services [7]. The ensuing work flexibility is expected to foster work-life balance, with positive implications for individual and group outcomes.

However, there is mixed evidence that the positive resources provided by collaborative spaces increase creativity and innovation $[4,8]$. For example, the open spaces that often characterize collaborative spaces can also reduce interactions and increase coordination costs [9]. Exemplar collaborative spaces, such as science parks, face difficulties in actually bringing together different parties and creating breakthrough innovations $[10,11]$.

In addition, the literature on collaborative spaces rarely takes into account the fact that CSs are used by individuals and groups on a temporary, part-time or irregular basis. For instance, inhabitants of co-working spaces do not typically spend their full working time within the space [12]. In other words, individuals work in and out of collaborative spaces and typically make an intensive use of collaborative technology to keep in touch with the different groups and individuals they work with (e.g., [13]). The literature on collaborative technology use and distributed work describes the challenges posed by the lack of proximity (e.g., reduced trust and knowledge sharing, increased conflict and coordination costs [14-16]. An intense use of collaborative technology, and the associated possible over-connectivity, could also affect the relationship between work-life balance and creativity. More recently, a few authors have started to recognize that the investigation of the impact of creative spaces on innovation cannot ignore the role played by collaborative technology use in everyday interactions between knowledge workers within and outside of collaborative spaces [7, 13, 17]. However, it is not clear how on-site experiences and technology mediated interactions interplay in creating affordances and constraints for innovation in collaborative spaces.

The objective of this paper is thus to provide a more nuanced view of creative processes within collaborative spaces by explicitly recognizing the fundamental role of collaborative technology use. In particular, we aim to explore how the positive resources related to wellbeing and work-life balance in collaborative spaces interplay with the use of collaborative technology in affecting individual creativity. In the next 
sections, we first present our hypotheses on the relationship between work-life balance, technology mediated interactions, and individual creativity in collaborative spaces. Then, we present the survey study we conducted in the collaborative spaces of one of the most industrialized regions in Europe. Finally, we illustrate our preliminary results and discuss their theoretical and practical implications.

\section{Hypotheses Development}

Figure 1 visually synthesizes the hypotheses that we are going to discuss next.

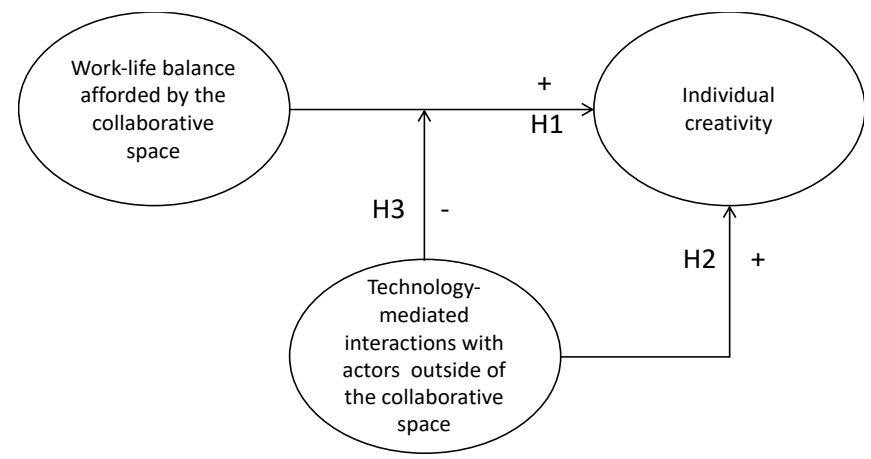

Fig. 1. Hypotheses.

\subsection{The effect of work-life balance on creativity in collaborative spaces}

Collaborative spaces are designed to offer flexibility to workers in terms of timing (flextime) and location (flexplace) of work (SHRM Foundation, 2001). Flextime refers to the 'ability of rearranging one's working hours within certain guidelines' (Hill et al., [18], p. 50), while flexplace reflects the degree of control given to workers over where to work [19]. Flextime and flexplace are resources intended to improve individuals' work-life balance (see [20]). Work-life balance refers to situations where individuals are equally satisfied and equally involved in their work and their family role [21]. Perceptions of work-family balance are strengthened by high levels of inter-role facilitation [22] that can be accrued by workers' flexibility in terms of time and space. For instance, the studies of Hammer et al. [23] and Hill and colleagues [18], although not conducted in collaborative spaces, found that the perceived flexibility in terms of time and space was associated to higher levels of work-family balance. Providing CS workers with a positive perception of the ability to manage the interface between work and life domains may lower negative emotions and increase workers' perception of control over their work environment [18, 24-27]. This, in turn, can help individuals to develop more and better ideas. In addition, an increased ability to manage the interface between work and life, thanks to a reduction of stress and perception of overload, has the potential to free individuals' cognitive resources and enhance creativity [28]. 
We thus hypothesize that the work-life balance experience through the participation in a collaborative space has a positive impact on individual creativity.

H1 The higher the perceived level of work-life balance experience through the CS, the higher the creativity

\subsection{The effect of technology mediated interactions on creativity in collaborative spaces}

While collaborative spaces offer numerous resources and inputs for individuals to develop creative ideas (e.g. [4, 8, 29]), workers do not carry out their tasks only within collaborative spaces and in collaboration with other members of CSs. They also maintain contacts with individuals outside of the collaborative space, making use of collaborative technology. Research on creativity has long established that 'external' ties have the power to foster innovative ideas. For instance, Perry-Smith [30] underlines how external connections may offer to individuals a wide range of ideas to draw on when tackling problems and developing solutions, stimulating divergent thoughts and enhancing creativity-related processes. Thus, external connections are expected not only to provide ideas to individuals but also to enhance and enlarge the way individuals think about problems.

Research on the use of collaborative technology has also shown the positive impact of collaborative technology use in getting access to distant resources that can foster creativity and innovation [15, 31-33]. We thus propose that:

H2 The higher the technology mediated interactions with external actors (outside of the $C S)$, the higher the creativity

\subsection{The interactive effect of work-life balance and technology mediated interactions on creativity in collaborative spaces}

While collaborative technology is deemed fundamental for the new world of work, it also poses serious challenges for individuals and groups in organizations. Literature on the disruptive effect of technology underlines how collaborative technology increases interruptions and disruptions on individuals' work, burdening them with an increased cognitive load (e.g. [34, 35]). We argue that, if individuals make an intense use of collaborative technology, they will be less able to take advantage of the wellbeing experience provided by the CS. We base our argument on the fact that a high use of technology may fragment one's attention over multiple resources, tasks and activities, and increase a person's reachability. In relation to the first mechanism, a higher work fragmentation, that has been associated to perceptions of overload [36] can counterbalance the positive effect on creativity coming from a reduced stress and reduced perception of role overload. In addition, the feeling of being always on, engendered by an intense use of collaborative technology, and coupled with the perception of being always available to others' requests, can generate additional perceptions of overload related to the sheer number of requests and the handling of multiple colleagues. Also, this latter mechanism can counterbalance the positive influence on creativity of an enhanced wok life balance provided by the CS. We thus propose that: 
H3 The positive relationship between work-life balance and creativity is negatively moderated by technology mediated interactions with external actors

\section{Data and Methods}

\subsection{Context and data}

Our study is based on data collected thorough a survey sent to individuals working in the collaborative spaces of an industrialized region of Northern Italy. The survey involved all the collaborative spaces located throughout the region, with greater density in larger cities. The survey reached individuals in different types of collaborative spaces, mainly co-working spaces (55\% of respondents), business incubators $(8 \%)$, science parks (20\%), and hybrid spaces (17\%). Co-working spaces are collaborative spaces that offer a work environment designed to allow users to work in the same way as they do in a traditional office, but shared with other workers, typically professionals, freelancers, or people who travel frequently. Members of co-working spaces work independently but typically share values and have interest in the synergy that can occur when working in contact with other people. In particular, co-working spaces are designed to promote creativity and productivity, thus combining the economic benefits of a shared office with an environment designed to stimulate innovation [7]. Business incubators or business centers are designed to accelerate the development of companies providing a series of resources to support businesses, services, and a network of contacts. Incubators vary in the way they provide their services, their organizational structure, and the type of customers they serve. Science parks are built to support and to promote technological transfer between universities, public organizations and private companies, and often host incubators of university spin-offs. Among the spaces studied, there are spaces that have features common to several types, i.e. hybrid spaces.

We first created a list of all the collaborative spaces of the region by looking at documents and searching on the web. The main keywords used were: "Name of province + collaborative spaces", "Name of province + incubator", + "Name of province + innovation hub", "Name of province + coworking", "Name of province + creative space". The initial list included 73 spaces. Since some of the spaces of our first list did not seem fully consistent with our definition of collaborative space (e.g. they appeared more as 'rented office space' than a co-working space), we called a referent person in those spaces to ask for more information. At the same time, we performed an accurate analysis of their website. As a consequence, we eliminated some of the spaces from our research. Our final list included 66 spaces. We then developed a multi-section questionnaire that explores the individual work-related and social experience within collaborative spaces, focusing on constructs such as work-life balance, face to face interactions, work interactions mediated by technology tools, perceptions of innovation climate, and creativity. The questionnaire was initially created in English and then translated into Italian with a translation-back translation procedure [37].

The survey was submitted to individuals working in all selected collaborative spaces. We got responses from 132 individuals working in 27 collaborative spaces (co-working, scientific park, hybrid, hub, business incubator). The average age of respondents 
was 37 years (s.d. $=8.9)$ and the majority of the population sample were males $(61 \%)$. $67 \%$ of the population sample declared themselves "self-employed". As far as their education is concerned, most of them had a graduate or undergraduate degree (master's degree $35 \%$, bachelor's degree $20 \%$ ), $21 \%$ held a high school diploma, $11 \%$ had a postgraduate degree master, and 5\% had a PhD.

\subsection{Measures and analyses}

Dependent variable. To measure creativity, we followed Sue-Chan and Hempel's [38] guidelines and recognized that novelty and usefulness are two components of creativity. Novelty was evaluated asking the degree of agreement on a 7-point Likert scale with the following statements: "I have original ideas", "I often have a fresh approach to problems", "I have a unique perspective", "I generate unprecedented solutions to a problem", "My solution is often different from traditional ways of doing a task", "My solution is out-of-the box" [38]. The Cronbach Alpha was 0.89.

Usefulness was evaluated using six items: "I develop solutions focused on the needs of the user, not on the functions of a product", "I produce simple solutions to problems", "I identify opportunities for implementing new products/processes", "I develop adequate plans for the implementation of new ideas", "I integrate multiple perspectives in a constructive manner", "I combine ideas in a constructive manner" [38]. The Cronbach Alpha was 0.85 .

Considering that Amabile [39-41], when referring to a product or service, defined creativity as new, appropriate or useful and since most of the studies concerning creativity in organizational field are consistent with the definition of Amabile (e.g. [42, 43]) we studied creativity as a composite measure computed as the average of novelty and usefulness $(\alpha=0.91)$.

Independent variables. We measured the individual experience of work-life balance using the scale of Work-life Balance Satisfaction developed by Valcour [44]. Respondents were asked to express their degree of satisfaction (using a Likert scale, from 1 - "very dissatisfied" to 7 - "very satisfied") with the following items: "The way you divide your time between work and personal or family life", "The way you divide your attention between work and home", "How well your work-life and your personal or family life fit together", "Your ability to balance the needs of your job with those of your personal or family life", "The opportunity you have to perform your job well and yet be able to perform home-related duties adequately". The Cronbach Alpha was 0.94.

The frequency of work interaction with external actors mediated by technology was collected through a 7-point frequency scale where: 1 - "never", 2 - "annually or less", 3 - "many times per year", 4 - "many times per month", 5 - "many times per week", 6 - "many times per day", 7 - "many times per hour", by asking to respondents to answer the following items: "How frequently do you have synchronous, i.e. same time, technology-mediated communication (e.g. phone calls, video conference, instant messaging) with others (e.g., work colleagues or clients who are not members of the CS)?", "How frequently do you have asynchronous technology-mediated interactions (e.g. exchange of emails, SMS, voice messages) with others (e.g., work colleagues or 
clients who are not members of the CS)?". The final variable we used was computed as the mean of the two measures.

Control variables. We used several control variables, i.e. climate for innovation, type of employment, education, gender, and age. The literature on creativity has shown how the climate for innovation promoted in the environment significantly influences the level of creativity of the outputs (e.g. [45, 46]). We, therefore, used the climate for innovation as a control variable. We adapted the scale designed by Scott and Bruce [47] for traditional organizational contexts to the case of a collaborative space and selected 4 meaningful items. In particular the survey asked to report on a 7-point Likert scale the level of agreement with the following statements: "Creativity is encouraged in this CS", "This CS can be described as flexible and continually adapting to change", "This CS is open and responsive to change", "Assistance in developing new ideas is readily available in this CS", "There are adequate resources devoted to innovation in this CS". The Cronbach Alpha was 0.92.

We considered that individuals who are self-employed may be more entrepreneurial and creative. Thus, we controlled for the form of employment with a dummy measure in which $0=$ Employed and $1=$ Self-Employed. We asked respondents to choose the employment status that best described them from a short list - created with 6 items reflecting the types of employment in Italy - and then merging the six collection items into the two macro categories.

The educational level may impact the ability of individuals to develop new ideas in specialized fields [48]. Thus, the educational level was collected asking to choose one of the following items: 1 secondary school, 2 professional qualification, 3 high school Diploma, 4 bachelor's degree, 5 master's degree, 6 master post degree, 7 Ph.D., 8 others.

We also controlled for gender with a dummy variable (coded $0=$ female, $1=$ male). Although there is no evidence that gender influences creativity, the literature recognizes that female professionals have sometimes fewer access to resources that can be fundamental to initiate and develop creative ideas [49].

Age may be a proxy of one's experiences. Previous experiences, especially in terms of breadth can be predictors of one's capability to spot new innovative courses of actions. We thus controlled for the age of each respondent, calculated from year of birth (reference year is 2018, when the data collection was completed).

Analyses. The described variables were used to run OLS models. Model 1 and 2 test the direct effects of the control and independent variables on creativity, through a multiple linear regression analysis. In order to test for moderation, we centered our variables. Model 3 tests the role of moderator of the frequency of work interactions with external actors mediated by the use of technologies, through a moderated multiple regression analysis. We used the variance inflation factor (VIF) to rule out issues of multicollinearity. The maximum VIF was 1.14 and the average VIF was 1.10. Therefore, we do not have reasons to suspect that multicollinearity was a problem. We recognize that common method bias may be a problem in our dataset. However, previous studies on individual creativity have extensively tested models where dependent and independent variables came from the same source, since "employees themselves are best suited 
to report creativity because they are aware of the subtle things they do in their jobs that make them creative" $[1,50,51]$.

In addition, we decided to keep self-reported variables considering the particular context of our study. CSs are mostly attended by self-employed professionals and freelancers, and these professions are practiced in multiple and distinct professional fields, for example, computer programming, design, journalism, etc. Given such heterogeneity, it would have been difficult, if not impossible, to identify a common source of external data on individual creativity (for example the number of awards received, or an evaluation provided by a client or another stakeholder).

Also, it would have been difficult, if not impossible, to ask other individuals (e.g. managers, stakeholders) to evaluate the creative performance of our informants, because many of the individuals working in collaborative spaces are freelancers and individual contractors. The managers of the CS do not have specific knowledge in all the occupational fields covered by coworkers, and it is difficult for them to have all the necessary information to judge the creativity of inhabitants of a CS.

We thus followed $\mathrm{Ng}$ and Feldman [52], who argue that the presence of individual and/or contextual factors can make the self-assessment of creativity acceptable or more appropriate. According to these authors, using creativity self-assessments is acceptable when the individual's creative changes or performance may not be visible to a third person. To conclude, in agreement with Kaufman [53], although self-assessment is not the best method to collect measures of individual creativity, it is acceptable when the conditions of research make it necessary.

To contain the effect of common method bias, in our questionnaire we separated the independent and dependent variables [54]. To further evaluate the problem, we computed the Harman's single factor test in which all items (measuring latent variables) are loaded into one common factor (Podsakoff et al., 2012). The total variance for a single factor was less than $50 \%$ (total variance $=0.32$ ), suggesting that common method bias did not affect your data, hence our results.

\section{Results}

Table 1 presents a correlation matrix and descriptive statistics for all the measured variables. Not surprisingly for collaborative spaces devoted to innovation, the descriptive statistics show high levels of perceptions of climate for innovation (mean $=5.24$, s.d. $=$ 1.39). Above average values were also recorded for the perception of the work-life balance satisfaction level (mean $=4.75$, s.d. $=1.33$ ) and for the frequency of work interactions with external actors mediated by technology $($ mean $=4.91$, s.d. $=1.63)$. In accordance with the hypotheses of our study, creativity is significantly and positively correlated with the level of personal satisfaction about work-life balance, as well as with the climate for innovation. Furthermore, there is also a positive correlation between creativity and frequency of work interaction with external actors mediated by technology. 
Table 1. Univariate statistics and Pearson correlations among study variables $(\mathrm{N}=132)$.

\begin{tabular}{|l|c|c|c|c|c|c|c|c|c|c|c|}
\hline & Mean & s.d. & Max & Min & 1 & 2 & 3 & 4 & 5 & 6 & 7 \\
\hline $\begin{array}{l}\text { 1. Employed } \\
\text { Vs Self- } \\
\text { Employed }\end{array}$ & 0.67 & 0.47 & 1 & 0 & 1.00 & & & & & & \\
\hline 2. Education & 4.67 & 1.40 & 8 & 2 & 0.09 & 1.00 & & & & & \\
\hline 3. Gender & 0.61 & 0.49 & 1 & 0 & -0.01 & $-0.28^{* *}$ & 1.00 & & & & \\
\hline 4. Age & 36.65 & 8.93 & 59 & 20 & $-0.18^{*}$ & $-0.15^{*}$ & 0.01 & 1.00 & & & \\
\hline $\begin{array}{l}\text { 5. Climate for } \\
\text { Innovation }\end{array}$ & 5.24 & 1.39 & 7 & 1.4 & $0.21^{*}$ & -0.06 & -0.03 & -0.05 & 1.00 & & \\
\hline $\begin{array}{l}\text { 6. Work Life } \\
\text { Balance }\end{array}$ & 4.75 & 1.33 & 7 & 1 & 0.13 & -0.09 & 0.02 & 0.03 & $0.20^{*}$ & 1.00 & \\
\hline $\begin{array}{l}\text { 7. Work } \\
\text { Interactions } \\
\text { (ext.) }\end{array}$ & 4.91 & 1.63 & 7 & 1 & -0.08 & -0.02 & 0.01 & $0.21^{*}$ & $0.19^{*}$ & 0.12 & 1.00 \\
\hline 8. Creativity & 5.09 & 0.91 & 7 & 1.58 & 0.14 & -0.11 & 0.09 & 0.05 & $0.38^{* *}$ & $0.26^{* *}$ & $0.19^{*}$ \\
\hline
\end{tabular}

Table 2 presents the results of the regression analysis. In model 1, only climate for innovation was significantly related to creativity $(\beta=0.24 ; p<0.001)$. The results of the regression in model 2 show the satisfaction of the individual work-life balance is positively associated to creativity $(\beta=0.12 ; \mathrm{p}<0.05)$, providing support for our first hypothesis, H1: The higher the perceived level of work-life balance experience through the collaborative space, the higher the creativity.

Our second hypothesis pertains to the direct effect of frequency of work interactions with external actors to CS enabled by technology, on creativity. In Model 2 there is not a significant relationship between technology mediated interactions and creativity, suggesting that $\mathrm{H} 2$ is not supported.

In model 3 we test the interaction effect between work-life balance experience through the collaborative space and technology mediated interactions with external actors on creativity. Consistently with $\mathrm{H} 3$, we find that the moderating effect is negative and significant $(\beta=-0.10 ; p<0.001)$. The plot in Figure 2 shows that, at low levels of technology mediated interactions with external actors, there is a positive relationship between work-life balance and creativity. However, at high levels of technology mediated interaction the effect of work-life balance on creativity seems marginal, if not negative.

Table 2. Results of regression analysis.

\begin{tabular}{|c|c|c|c|c|c|c|c|c|c|}
\hline & \multicolumn{3}{|c|}{ Model 1 } & \multicolumn{3}{c|}{ Model 2 } & \multicolumn{3}{c|}{ Model 3 } \\
\hline & Estimate & $\begin{array}{c}\text { Std. } \\
\text { Error }\end{array}$ & p-value & Estimate & $\begin{array}{c}\text { Std. } \\
\text { Error }\end{array}$ & p-value & Estimate & $\begin{array}{c}\text { Std. } \\
\text { Error }\end{array}$ & p-value \\
\hline (Intercept) & 3.54 & 0.57 & 0.00 & 2.96 & 0.61 & 0.00 & 0.64 & 0.90 & 0.48 \\
\hline Employed Vs Self-Employed & 0.17 & 0.16 & 0.30 & 0.15 & 0.16 & 0.35 & 0.22 & 0.16 & 0.17 \\
\hline Education & -0.04 & 0.06 & 0.47 & -0.03 & 0.06 & 0.54 & -0.02 & 0.05 & 0.65 \\
\hline Gender & 0.16 & 0.16 & 0.32 & 0.15 & 0.15 & 0.32 & 0.19 & 0.15 & 0.19 \\
\hline Age & 0.01 & 0.01 & 0.37 & 0.00 & 0.01 & 0.59 & 0.01 & 0.01 & 0.44 \\
\hline Climate for Innovation & $0.24^{* * *}$ & 0.05 & 0.00 & $0.20^{* * *}$ & 0.06 & 0.00 & $0.19^{* * *}$ & 0.05 & 0.00 \\
\hline Work-life Balance & & & & $0.12^{*}$ & 0.06 & 0.04 & $0.61^{* * *}$ & 0.16 & 0.00 \\
\hline Work Interactions (ext.) & & & & 0.06 & 0.05 & 0.19 & $0.52^{* * *}$ & 0.14 & 0.00 \\
\hline $\begin{array}{c}\text { Work-life Balance *Work } \\
\text { Interactions (ext.) }\end{array}$ & & & & & & & $-0.10^{* * *}$ & 0.03 & 0.00 \\
\hline
\end{tabular}

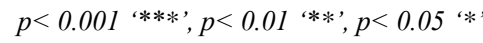




\begin{tabular}{|c|c|c|c|}
\hline & Model 1 & Model 2 & Model 3 \\
\hline Observations & 132 & 132 & 132 \\
\hline R2 & 0.17 & 0.21 & 0.28 \\
\hline Adjusted R2 & 0.14 & 0.17 & 0.23 \\
\hline Residual Std. Error & $0.85(\mathrm{df}=126)$ & $0.83(\mathrm{df}=124)$ & $0.80(\mathrm{df}=123)$ \\
\hline F Statistic & $5.12(\mathrm{df}=5 ; 126)$ & $4.72(\mathrm{df}=7 ; 124)$ & $5.90(\mathrm{df}=8 ; 123$ \\
\hline
\end{tabular}

The frequency of work interactions mediated by collaborative technology was investigated through two separate questions asked to respondents: one referring to synchronous technology interaction work (e.g., via conference calls) and the other related to asynchronous technology interaction work (e.g. through emails). By analyzing the data of the single answers, it is possible to further deepen our analysis. We re-ran models 2 and 3, using synchronous technology mediated interactions with external actors and asynchronous technology mediated interactions with external actors. The results of these four new models replicate the results already discussed of model 2 and model 3 in Table 2, i.e. there is no different effect on the dependent variable if the technologies that mediate the working interaction are synchronous or asynchronous.

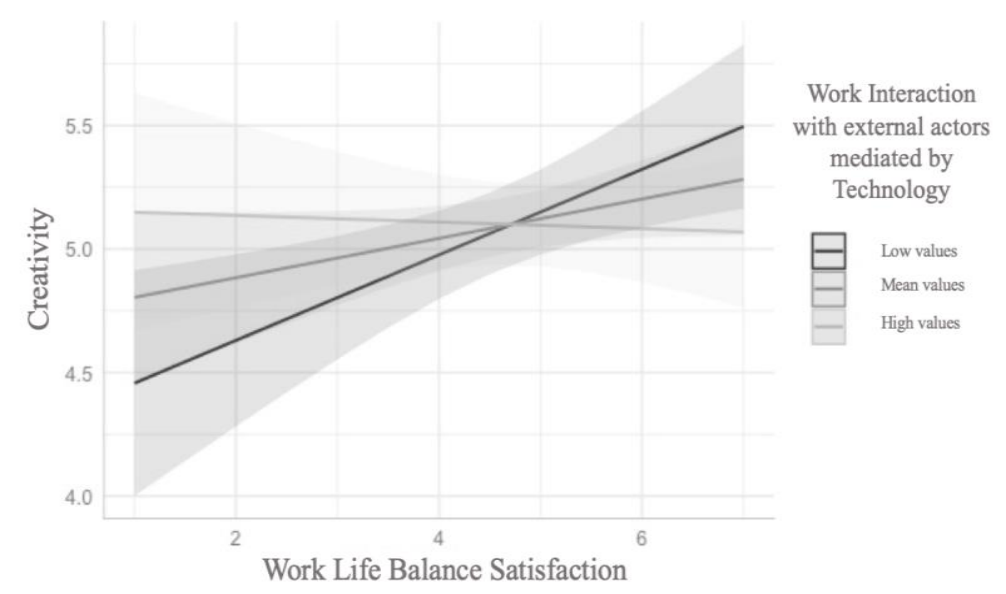

Fig. 2. Plot of interaction effect between technology mediated interactions with external actors and work-life balance on creativity

\section{$5 \quad$ Discussions and conclusions}

The aim of this paper was to investigate the experience of professionals working in collaborative spaces, such as co-working spaces and innovation labs, created for enhancing individual and group creativity. We wanted to move beyond the common rhetoric that collaborative spaces impact on creativity by increasing individual well-being and by stimulating face to face interactions (e.g., $[7,55])$ and recognize the fundamental role played by collaborative technology in such environments. Our study focused on 
how the positive resources related to work-life balance in collaborative spaces interplay with the use of collaborative technology in affecting individual creativity.

Our survey analysis, conducted in 27 collaborative spaces in a highly industrialized area of Northern Italy, provides support for our theorizing. In particular, we first hypothesized and found that perceptions of work-life balance are positively associated to increased creativity in collaborative spaces. These results are in accordance with previous literature that has linked the implications of a positive interface between work and life domains to individual success in organizations [56]. Most of the literature on worklife balance, however, is based on empirical data collected in traditional work contexts, e.g. large companies, public organizations, small and medium enterprises [57], and often does not take into account the changing nature of the workplace. Research has recently started to address the issue of work-life balance in relation to telework, smart work, and flexible work arrangements (e.g., [58, 59]). Our research contributes to this emerging debate by showing the importance of work-life balance for innovation in nontraditional contexts, in particular in collaborative spaces.

Second, we hypothesized that technology mediated interactions with actors outside of the CS are related to increased creativity. In CSs multiple opportunities are offered to interact face to face with other occupants of the space, e.g. meetings, social events, spatial features. Technology mediated interactions are fundamental to get in, or maintain, interaction with external actors. Such external interactions are instrumental to get new ideas, to access resources, and to be exposed to different points of view. However, contrary to our expectations, our second hypothesis was not supported because we did not find a significant effect for the relationship between the aggregated measure of technology mediated interactions and creativity and the same happened when we distinguished between synchronous and asynchronous technology use.

The role and implications of technology-mediated interactions (both synchronous and asynchronous) are further elucidated by the results of our third hypothesis that shows how the effect of work-life balance on creativity is negatively moderated by the frequency of technology mediated interactions with external actors. Thus, our results point out that the ability to exploit the positive resources developed thanks to the experience in CS (in our case in terms of enhanced work-life balance afforded by increase work flexibility) is contingent to the way individuals make use of other types of resources (in our case collaborative technology). Requests and interactions (both in real time or deferrable), arguably through an increase in the perception of role overload, may reduce the positive implications of the wellbeing offered by a collaborative space to creativity, thus providing a more nuanced understanding of how creative processes play out in new flexible and boundaryless workplaces. These results also contribute to understand the implications of collaborative technology on innovative and creative work in general, and in collaborative spaces in particular. Interestingly, very few organizational scholars have specifically taken into account the role of technology mediated interactions on creativity (see Burkhardt et al., [60] for a meaningful example) and none have considered the diverse effects provided by different types of mediated interactions. We thus contribute to this emerging field.

This work offers practical implications for designers, managers, and workers of collaborative spaces. First, when designing collaborative spaces, architects and designers 
should consider the sociotechnical nature of a collaborative space. They should design the physical characteristics of the space taking into account (and possibly integrating within their design) the role played by collaborative technology. Managers of collaborative spaces should be aware of the fundamental role played by collaborative technology in fostering innovation results. Even if we know that collaborative spaces allowing spontaneous interactions may favor unexpected forms of knowledge exchanges also between people belonging to different communities [61], space managers should not just focus on fostering face to face interactions within the space, by also offer additional opportunities for interactions with external actors. For instance, they could institute webinars or offer specific platforms that could be accessed both by members of the space as well as by external constituencies. However, in doing so, they should be careful in not overwhelming individuals with technologies that require them to be always 'on'. Finally, workers should recognize that the wellbeing guaranteed by the space may lead to their increased creativity only when they enact certain interaction patterns. Enacting a targeted and 'regulated' use of collaborative technologies with actors outside of the space may be a strategy to get the best out of the flexibility offered by a collaborative space.

This work is not, of course, without limitations. We collected our data in a limited number of spaces and with a limited number of respondents. Although the context of our data collection (a highly industrialized area) is extremely relevant and representative of knowledge intensive contexts, future work should replicate and extend our study in other contexts. The dataset we have used relies on data coming from a single source. Although we have ruled out possible issues related to common method bias, future studies should explore ways to assess creativity outcomes through other sources (expert evaluations, documents, client's evaluations). Although it is not easy to obtain multisources for the detection of individual creativity in the context examined, and, as already discussed in the methodology, there is a theoretical motivation for using selfassessment to measure creativity, we believe it is useful to try to integrate the study with additional measures of creativity coming from other sources, such as opinions of clients and supervisors of freelances or peers. As an alternative measure, it could be interesting to develop a new measure of self-assessment of creativity that incorporates assessments from freelances at different points in time.

Our paper has started to explore the different roles played by different technologies on the work experiences of inhabitants of collaborative spaces. We believe more efforts should be put in place to distinguish the different uses and affordances of collaborative technology in collaborative spaces, for instance by distinguishing different type of technology (e.g., social media, instant messaging system), the provider of the technology (e.g., the individual worker, the collaborative space), and the multiple interpretations that different professionals may develop about the use of a technology (e.g., designers, engineers, creative workers).

Another direction for future research could be investigating whether the type of profession may differentially affect creativity processes in the context of CSs. We propose to distinguish professions into macro-categories, for instance technology-oriented professions and non-technology-oriented professions. This way we can create a dummy 
variable that could act as a control variable for the professional background and test if it plays a direct or moderating role.

Another possible avenue could be to investigate how collaborative spaces can reduce the negative effect of technology in relation to the work-life balance of the individual. Indeed, these spaces can offer physical and mental boundaries to the worker, thanks to which workers could better manage their online status, thus becoming more focused on their task, instead of being continually distracted by the invasiveness of technology.

\section{References}

1. Dul J., Ceylan C., Jaspers F.: Knowledge workers' creativity and the role of the physical work environment. Human resource management 50, 715-734 (2011).

2. Kristensen T.: The physical context of creativity. Creativity and innovation management 13, 89-96 (2004).

3. Haner U. E.: Spaces for creativity and innovation in two established organizations. Creativity and innovation management 14, 288-298 (2005).

4. Moultrie J., Nilsson M., Dissel M., Haner U. E., Janssen S., Van Der Lugt R.: Innovation spaces: Towards a framework for understanding the role of the physical environment in innovation. Creativity and innovation management 16, 53-65 (2007).

5. Oksanen K., Ståhle P.: Physical environment as a source for innovation: investigating the attributes of innovative space. Journal of knowledge management 17, 815-827 (2013).

6. Garrett L. E., Spreitzer G. M., Bacevice P. A.: Co-constructing a sense of community at work: The emergence of community in coworking spaces.

Organization Studies 38, 821-842 (2017).

7. Errichiello L., Pianese T.: Smart work centers as "creative workspaces" for remote employees. CERN IdeaSquare Journal of Experimental Innovation 2, 14-21 (2018).

8. Vignoli M., Mattarelli E., Mäkinen S. J.: Experimenting with innovation in creative spaces. CERN IdeaSquare Journal of Experimental Innovation 2(1), 1-2 (2018).

9. J. P. B. H. P.: How to make sure your people won't hate your new open office plan. Harvard Business Review (2018).

10. Skelcher C., Mathur N., Smith M.: The public governance of collaborative spaces: Discourse, design and democracy. Public administration 83, 573-596 (2005).

11. Ungureanu P., Bertolotti F., Macri D.: Brokers or platforms? A longitudinal study of how hybrid interorganizational partnerships for regional innovation deal with VUCA environments. European Journal of Innovation Management 21, 636-671 (2018).

12. Spinuzzi C.: Working alone together: Coworking as emergent collaborative activity. Journal of Business and Technical Communication 26, 399-441 (2012).

13. Ungureanu P., Cochis C., Rodighiero S., Bertolotti F., Mattarelli E., Montanari F., Rinaldini M., Scapolan A. C.: Innovating onsite or 
coordinating online? An exploration of how knowledge practices shape the onsite and online collaboration interplay across the lifecycle of collaborative communities. CERN IdeaSquare Journal of Experimental Innovation 2, 2229 (2018).

14. Crisp C. B., Jarvenpaa S. L.: Swift trust in global virtual teams. Journal of Personnel Psychology (2013).

15. Gupta A., Mattarelli E., Seshasai S., Broschak J.: Use of collaborative technologies and knowledge sharing in co-located and distributed teams: Towards the 24-h knowledge factory. The Journal of Strategic Information Systems 18, 147-161 (2009).

16. Poliandri V., Mattarelli E., Bertolotti F., Tagliaventi M. R., Grandi A.: Integrating Knowledge through Consistency between Leadership and Technology in Distributed Teams. In: Academy of Management Proceedings. Academy of Management Briarcliff Manor, NY 10510, 15767 (2014).

17. Cirella S., Yström A.: Creativity and science parks: more than just a physical platform? CERN IdeaSquare Journal of Experimental Innovation 2, 8-13 (2018).

18. Hill E. J., Hawkins A. J., Ferris M., Weitzman M.: Finding an extra day a week: The positive influence of perceived job flexibility on work and family life balance. Family relations 50, 49-58 (2001).

19. Shockley K. M., Allen T. D.: When flexibility helps: Another look at the availability of flexible work arrangements and work-family conflict. Journal of Vocational Behavior 71, 479-493 (2007).

20. Beauregard T. A., Henry L. C.: Making the link between work-life balance practices and organizational performance. Human resource management review 19, 9-22 (2009).

21. Greenhaus J. H., Collins K. M., Shaw J. D.: The relation between workfamily balance and quality of life. Journal of vocational behavior 63, 510531 (2003).

22. Frone M. R.: Work-family balance. Handbook of occupational health psychology 7, 143-162 (2003).

23. Hammer L. B., Allen E., Grigsby T. D.: Work-family conflict in dual-earner couples: Within-individual and crossover effects of work and family. Journal of vocational behavior 50, 185-203 (1997).

24. Anderson S. E., Coffey B. S., Byerly R. T.: Formal organizational initiatives and informal workplace practices: Links to work-family conflict and jobrelated outcomes. Journal of management 28, 787-810 (2002).

25. Kossek E. E., Ozeki C.: Bridging the work-family policy and productivity gap: A literature review. Community, Work \& Family 2, 7-32 (1999).

26. Saltzstein A. L., Ting Y., Saltzstein G. H.: Work-family balance and job satisfaction: The impact of family-friendly policies on attitudes of federal government employees. Public administration review 61, 452-467 (2001).

27. Thomas L. T., Ganster D. C.: Impact of family-supportive work variables on work-family conflict and strain: A control perspective. Journal of applied psychology 80, 6 (1995). 
28. Florida R., Goodnight J.: Managing for creativity. Harvard business review 83, 124 (2005).

29. Capdevila I.: Co-working spaces and the localised dynamics of innovation in Barcelona. International Journal of Innovation Management 19, 1540004 (2015).

30. Perry-Smith J. E.: Social yet creative: The role of social relationships in facilitating individual creativity. Academy of Management journal 49, 85101 (2006).

31. Malhotra A., Majchrzak A., Carman R., Lott V.: Radical innovation without collocation: A case study at Boeing-Rocketdyne. MIS quarterly 229-249 (2001).

32. Yoo Y., Henfridsson O., Lyytinen K.: Research commentary-the new organizing logic of digital innovation: an agenda for information systems research. Information systems research 21, 724-735 (2010).

33. Standing C., Kiniti S.: How can organizations use wikis for innovation? Technovation 31, 287-295 (2011).

34. Speier C., Valacich J. S., Vessey I.: The influence of task interruption on individual decision making: An information overload perspective. Decision Sciences 30, 337-360 (1999).

35. Karr-Wisniewski P., Lu Y.: When more is too much: Operationalizing technology overload and exploring its impact on knowledge worker productivity. Computers in Human Behavior 26, 1061-1072 (2010).

36. Zika-Viktorsson A., Sundström P., Engwall M.: Project overload: An exploratory study of work and management in multi-project settings. International Journal of Project Management 24, 385-394 (2006).

37. Brislin L., Lonner W.: Thorndike. Cross Cultural Research Methods. John Wiley and Sons: New York (1973).

38. Sue-Chan C., Hempel P. S.: The creativity-performance relationship: How rewarding creativity moderates the expression of creativity. Human Resource Management 55, 637-653 (2016).

39. Amabile T. M.: Social psychology of creativity: A consensual assessment technique. Journal of personality and social psychology 43, 997 (1982).

40. Amabile T. M.: The social psychology of creativity: A componential conceptualization. Journal of personality and social psychology 45, 357 (1983).

41. Amabile T. M.: A model of creativity and innovation in organizations. Research in organizational behavior 10, 123-167 (1988).

42. Zhou J., George J. M.: When job dissatisfaction leads to creativity: Encouraging the expression of voice. Academy of Management journal 44, 682-696 (2001).

43. Oldham G. R., Cummings A.: Employee creativity: Personal and contextual factors at work. Academy of management journal 39, 607-634 (1996).

44. Valcour M.: Work-based resources as moderators of the relationship between work hours and satisfaction with work-family balance. Journal of applied psychology 92, 1512 (2007).

45. West M. A.: The social psychology of innovation in groups. (1990). 
46. Eisenbeiss S. A., Van Knippenberg D., Boerner S.: Transformational leadership and team innovation: Integrating team climate principles. Journal of applied psychology 93, 1438 (2008).

47. Scott S. G., Bruce R. A.: Determinants of innovative behavior: A path model of individual innovation in the workplace. Academy of management journal 37, 580-607 (1994).

48. Fasko D.: Education and creativity. Creativity research journal 13, 317-327 (2001).

49. Ibarra H.: Homophily and differential returns: Sex differences in network structure and access in an advertising firm. Administrative science quarterly 422-447 (1992).

50. Baer M.: Putting creativity to work: The implementation of creative ideas in organizations. Academy of Management Journal 55, 1102-1119 (2012).

51. Shalley C. E., Gilson L. L., Blum T. C.: Interactive effects of growth need strength, work context, and job complexity on self-reported creative performance. Academy of Management journal 52, 489-505 (2009).

52. Ng T. W., Feldman D. C.: A comparison of self-ratings and non-self-report measures of employee creativity. Human Relations 65, 1021-1047 (2012).

53. Kaufman J. C.: Self-assessments of creativity: Not ideal, but better than you think. Psychology of Aesthetics, Creativity, and the Arts 13, 187 (2019).

54. Podsakoff P. M., Mackenzie S. B., Lee J.-Y., Podsakoff N. P.: Common method biases in behavioral research: A critical review of the literature and recommended remedies. Journal of applied psychology 88, 879 (2003).

55. Khazanchi S., Sprinkle T. A., Masterson S. S., Tong N.: A spatial model of work relationships: The relationship-building and relationship-straining effects of workspace design. Academy of Management Review 43, 590-609 (2018).

56. Wayne J. H., Butts M. M., Casper W. J., Allen T. D.: In search of balance: A conceptual and empirical integration of multiple meanings of work-family balance. Personnel Psychology 70, 167-210 (2017).

57. Johari J., Yean Tan F., Tjik Zulkarnain Z. I.: Autonomy, workload, work-life balance and job performance among teachers. International Journal of Educational Management 32, 107-120 (2018).

58. Hilbrecht M., Shaw S. M., Johnson L. C., Andrey J.: 'I'm home for the kids': contradictory implications for work-life balance of teleworking mothers.

Gender, Work \& Organization 15, 454-476 (2008).

59. Holland P., Bardoel A.: The impact of technology on work in the twenty-first century: exploring the smart and dark side. In: Taylor \& Francis, (2016).

60. Burkhardt J.-M., Lubart T.: Creativity in the age of emerging technology: Some issues and perspectives in 2010. Creativity and innovation management 19, pp 160-166 (2010).

61. Ungureanu, P., Bertolotti, F.: Building and breaching boundaries at once: An exploration of how management academics and practitioners perform boundary work in executive classrooms. Academy of Management Learning \& Education, 17(4), 425-452 (2018). 